\title{
A case of atypical disseminated herpes zoster in a patient with COVID-19; a diagnostic challenge in COVID era
}

\author{
fatemeh mohaghegh ${ }^{1}$, Parvaneh Hatami ${ }^{2}$, and Zeinab Aryanian ${ }^{2}$ \\ ${ }^{1}$ Isfahan University of Medical Sciences \\ ${ }^{2}$ TUMS
}

December 12, 2021

\begin{abstract}
The rare disseminated form of Herpes Zoster occurred mainly in immunocompromised patients. We hereby, present the first case of atypical disseminated herpes zoster in a 54-year old woman admitted with serious COVID. This case serves as a reminder for considering atypical presentations of cutaneous disorders in immunocompromised patients.
\end{abstract}

Hosted file

herpes zoster-covid(1)(1)(1).doc available at https://authorea.com/users/310715/articles/ 549025-a-case-of-atypical-disseminated-herpes-zoster-in-a-patient-with-covid-19-adiagnostic-challenge-in-covid-era 